\title{
Non-Cracked Epoxy Nanogel Composite as Anticorrosive Coatings for Aggressive Marine Environment
}

\author{
Mohamed H. Wahby ${ }^{1}$, Ayman M. Atta ${ }^{1,2,3 *}$ Hamad A. Al-Lohedan ${ }^{2}$,Ashraf M. El-saeed ${ }^{2}$, \\ Ahmed M. Tawfik ${ }^{4}$ \\ ${ }^{1}$ Department of Chemistry, Surfactant Research Chair, College of Science, King Saud University, \\ Riyadh 11451, Saudi Arabia \\ ${ }^{2}$ surfactants research chair, Department of Chemistry, Surfactant Research Chair, College of Science, \\ King Saud University, Riyadh 11451, Saudi Arabia \\ ${ }^{3}$ Petroleum application department, Egyptian petroleum research institute, Nasr city 11727, Cairo, \\ Egypt. \\ ${ }^{4}$ College of Science, King Saud University, Riyadh 11451, Saudi Arabia. \\ *E-mail: khaled 00atta@yahoo.com
}

doi: $10.20964 / 2017.01 .33$

Received: 7 October 2016 / Accepted: 8 November 2016 / Published: 12 December 2016

Cured epoxy coating crack is one of the drawbacks that can be solved by using self-healing preembedded nanomaterials to be an advanced prospective approach. In this work sodium montmorillonite modified with crosslinked nanogels based on smart sensitive $\mathrm{N}$-isopropyl acrylamide (NIPAm) copolymers with nonionic monomer as N-vinyl pyrrolidone (VP) and ionic monomer of 2acrylamido-2-methyl propane sulfonate sodium salt (AMPS-Na). The particle size, morphology, zeta potential, thermal stability and surface activity of Na-MMT nanogel in distilled and sea water were determined. The blending of Na-MMT nanogels with epoxy during the curing and their effects on exfoliation of Na-MMT and morphology were investigated. The corrosion inhibition efficiency of the cured epoxy embedded with Na-MMT nanogel as organic coats for steel was studied using salt spray resistance up to $1000 \mathrm{~h}$.

Keywords: Embedded epoxy, Coatings, Salt spray, corrosion inhibition, steel.

\section{$\underline{\text { FULL TEXT }}$}

(C) 2017 The Authors. Published by ESG (www.electrochemsci.org). This article is an open access article distributed under the terms and conditions of the Creative Commons Attribution license (http://creativecommons.org/licenses/by/4.0/). 